\title{
Purification and characterisation of cell survival factor 1 (TCSF1) from Tetrahymena thermophila
}

\author{
Morten I. Rasmussen • Denys N. Wheatley
}

Received: 21 June 2007 / Accepted: 26 December 2007 / Published online: 27 January 2008

(C) The International CCN Society 2007

\begin{abstract}
Of a number of peptides isolated from the extracellular medium of Tetrahymena cultures, two with masses 9.9 and $22.4 \mathrm{kDa}$ allowed low-density cultures of this ciliate to survive and enter a proliferate phase. The smaller peptide (TCSF1) also greatly helped cultured mammalian fibroblasts to survive in medium containing very low concentrations of serum for considerably longer than controls, and to grow when full strength medium was restored. The primary sequence of the TCSF1 was determined, and synthetic TCSF1 was observed to exhibit rescuing activity comparable to that of the native peptide.
\end{abstract}

Keywords Tetrahymena - Growth factors .

Cross-phyla responses $\cdot$ Low cell density $\cdot$ Survival

$\begin{array}{ll}\text { Abbreviations } \\ \text { TPAF } & \text { Tetrahymena } \text { proliferation activating factor } \\ \text { TCSF1 } & \text { Tetrahymena cell survival factor } \\ \text { CDM } & \text { chemically defined medium }\end{array}$

\section{Introduction}

Cells secrete signalling compounds, which keep themselves and their neighbour cells alive, and may assist them back into the proliferative mode when cell divisions occur faster than cells die Rasmussen et al. (1996). Cultured cells

\footnotetext{
M. I. Rasmussen

Aberdeen, UK

e-mail: artbreak@post.tele.dk

Present address:

D. N. Wheatley $(\triangle)$

Aberdeen AB51 OLX, UK

e-mail: wheatley@abdn.ac.uk
}

frequently require a certain initial density in order to "take" and proliferate past this crucial balance point, an often annoying feature of cells (and not just mammalian cells, see below) that has long been observed, but for which there could be a myriad explanations. Plating at low cell densities has been the bane of cloning, especially of sensitive cells that are invariably difficult to grow even in relatively crowded conditions. Conditioned medium has been the long-established method for improving cell cloning, but the growth factors already present in any serum supplement used for mammalian cells has made it extremely difficult to isolate, identify and analyse the functions of the effective molecules. It is clear that cells thrive better when clustered together, particularly where they can maintain direct contact with one another, which indicates auto- and paracrine mechanisms of "self stimulation", which might be so crucial at extremely low densities.

This difficulty is not confined to mammalian cells; cultured ciliata (protozoan) cells are no exception, since they secrete a number of regulatory factors to the extracellular medium that has autocrine and paracrine effects on growth. We know that the robust and usually fast-growing ciliate, Tetrahymena thermophila, grows exceedingly slowly, if at all, at culture densities of $\sim 500$ cells per ml. Cells fail to thrive below this critical density, and they die under nutritionally replete conditions Christensen et al. (1995, 2001), Szablewski et al. (1991). Above the critical concentration, cells "take" with little delay and grow exponentially in the very same medium, reaching millions of cells per ml within 2 days. It had long been suspected that signal molecules sent between cells are important, and that the physical distances between individual cells at high dilutions (i.e. at low inoculum levels) are too great for signalling purposes on a basis of free diffusion, and they do not generally support survival of enough cells to allow 
them to start proliferating. A crucial balance point therefore exists; if cells can survive long enough at this point they soon start exponential proliferation. If the cells cannot sustain themselves, they die with first order kinetics (Rasmussen and Rasmussen 2000a, b). Clearly any substance that helps cells to survive for long enough to allow them to respond to the effects of paracrine stimulants should lower the initial inoculum level from which cultures can "take". TCSF1 is such a signal peptide. Its action seems to be directed towards survival as distinct from stimulating division because, per se, it has little or no growth promoting action.

Single Tetrahymena cells can stimulate themselves to survive and proliferate in a defined and lipid-free medium. In rich media (yeast extract and/or proteose peptone), potent signal-like molecules allow growth from just a few cells per $\mathrm{ml}$, which is why chemically defined media (CDM; Szablewski et al. 1991) are essential for work on subtle signalling of the type to be discussed here. Thus Tetrahymena is similar to a mammalian cell in that it depends on compounds present in proteose-peptone (cf. serum; Yin and Wheatley 1994) for this signalling, but the value of working with $T$. thermophila is that because it can be cultured in CDM, molecules that cells secrete for paracrine stimulation can be picked up, isolated, purified, identified, and assayed against a relatively "noiseless" background.

Spent (conditioned) medium from Tetrahymena cultures can rescue cells from "low density death" when added to fresh CDM. Schousboe et al. (1997) demonstrated that a 4$6 \mathrm{kDa}$ filtrate of spent medium contained a substance that stimulated cell proliferation with an activity comparable to that of the complete spent medium; the substance was called TPAF (Tetrahymena Proliferation Activating Factor). Moving on from these earlier observations, the present paper establishes a protocol for purifying two biologically active factors, one of which might previously has been TPAF, but on several characteristics has a different identity. Since it acts mostly as a cell survival factor, it has been referred to as TCSF1.

\section{Materials and methods}

\section{Cell growth}

Tetrahymena thermophila (strain 1868) were kept in a standard defined medium Szablewski et al. (1991) in $3 \mathrm{ml}$ cultures at a constant temperature of $37^{\circ} \mathrm{C}$. Medium was changed in the stock cultures every week, and 1 day prior to an experiment; $500 \mathrm{ml}$ bulk cultures were grown in 51 conical flasks.

Tetrahymena excretes melanin precursors into the culture medium where spontaneous polymerisation to melanin occurs (Kaney and Knox 1980). This melanin elutes slowly from the HPLC column and makes purification of TCSF1 difficult. The precursors, probably oxidation products of catecholamines, are produced by decarboxylation of tyrosine and hydroxylation of the resulting tyramine. The growth medium was therefore formulated without tyrosine in this series of experiments. There was no measurable difference in cell growth between tyrosine-free CDM cultures and controls (data not shown).

FF9 (i.e. passage 9 of fibroblasts grown as a primary culture from a skin biopsy of an adult patient) and $3 T 3$ (supplied by ECACC) cells were grown in $25 \mathrm{ml}$ culture flasks with $15 \mathrm{ml}$ RPMI 1640 medium at a constant temperature of $37^{\circ} \mathrm{C}$ on a $5 \% \mathrm{CO}_{2}$ in air atmosphere. Medium containing 5\% serum was added to the stock cultures and changed at weekly intervals. Both cell types used for experimental purposes were carried out in $15 \mathrm{ml}$ RPMI 1640 in $25 \mathrm{ml}$ culture flasks, in which the level of serum supplement was adjusted as required to regulate growth rate (from 0.2 to $5.0 \%$ ).

Purification of the TCSF1 and isolation of its active components

Spent cell-free medium from $T$. thermophila cultures grown to near maximum was freeze-dried and resuspended in water to 40 fold greater than its original concentration. Salt precipitate forms at this concentration, and is subsequently removed by centrifugation and discarded. Concentrated, desalted spent medium was separated by reverse phase HPLC, using a column that consisted of $50 \%$ C8 Poros material and 50\% C18 Poros R1 material. This combination of materials gave good resolution in the $6-14 \mathrm{kDa}$ range, combined with a weak ion exchange. Proteins were eluted using a gradient of $5-70 \%$ acetonitrile in $0.01 \%$ TFA in steps of $10 \%$ intervals. The collected fractions were further separated on an $18 \%$ native gel, using SDS-free Laemmli buffer and stained with Novex colloidal blue (InVitrogen, Paisley, UK). The gel bands were cut out, frozen and defrosted twice to make the gel brittle. Crushed gel was mixed with $10 \mathrm{ml} 90 \%$ acetonitrile and stirred with a magnetic stirrer for $3 \mathrm{~h}$. Ten milliliters $0.1 \%$ TFA was added and stirred for an additional $3 \mathrm{~h}$. The supernatant of each fraction was collected and dried. The material was subjected to amino acid sequencing (see below), which was done on gel-purified material from the HPLC fractions, as just described.

Peptide synthesis

TCSF1 peptides were synthesized on a Pioneer Peptide Synthesis System. This system performs a solid-phase peptide synthesis, which automates the Fmoc (9-fluoronyl- 
methoxy-carbonyl) continuous flow method. The C-terminal of the supplied amino acid was coupled to a PEG-PS support, and the amino acids were sequentially coupled after the removing of the Fmoc- blocking group at each cycle.

The reagents used were $20 \%$ piperidine in dimethyl formaldehyde for the deblocking and HATU ( $N$-[dimethylamino-1-H-1,2,3-triazolo[4,5-b]pyridine-1-ylmethylene]- $\mathrm{N}$ methylmethanaminium hexafluorophosphate $\mathrm{N}$-oxide) for the coupling steps, as recommended by the manufacturer.

The peptide was cleaved and protected from the PEGPS support for approximately $4 \mathrm{~h}$ with $[1.76 \mathrm{ml}$ TFA: $100 \mathrm{mg}$ dithiothretiol (DTT): $100 \mu \mathrm{L}$ triisopropylsilane] followed by precipitation and purification with tertbutylether.

Prior to use, the purity of synthetic TCSF1 was verified with Maldi-MS.

\section{Results}

Growth-stimulating activity in HPLC fractions

Concentrated conditioned medium $(200 \mu \mathrm{l})$ from cultures of T. thermophila was separated on HPLC as described, and the fractions were collected. The injected volume corresponded to $8 \mathrm{ml}$ conditioned medium added to $3 \mathrm{ml}$ fresh medium, i.e. a 2.6-fold concentration of the active component (no estimate was made of the amount of activity lost during purification). Lyophilised fractions were resuspended in $3 \mathrm{ml}$ fresh medium and cells inoculated at a density of 100 cells $/ \mathrm{ml}$. Cells were counted after $24 \mathrm{~h}$, the data showing that TCSF1 elutes primarily at $40-50 \%$ acetonitrile (Fig. 1).
Growth stimulating activity of gel bands

Five samples of each of HPLC fractions 30,40 and $50 \%$ were pooled and separated on SDS-free, non-reducing gels (Fig. 2). The individual proteins were extracted from the gel according to the described protocol. Cells were inoculated below critical density $(10$ cells $/ \mathrm{ml})$ in $3 \mathrm{ml}$ medium, supplemented with the purified proteins. The cell density in triplicate cultures was counted after $24 \mathrm{~h}$ and the experiments were repeated 5 times. The extracted gel bands $7 \mathrm{~b}$ and 12 rescued the cells from dying (Fig. 3a, b), while less activity was observed in the neighbouring bands 7 , 8 and 13. Maldi MS determined the weight of the two peptides as 8.8 and $17.3 \mathrm{kDa}$.

Protein sequence of the active fractions

Active protein was isolated from the conditioned medium with HPLC, using a sloping gradient, and the mass of the peptide was determined to be $9.9 \mathrm{kDa}$ with Maldi MS (for comparison with the peptides referred to above with regard to $\mathrm{M}_{\mathrm{R}}$ see "Discussion" below). The peptide was sequenced by classical Edman degradation. This extractions and purification consistently gave a sequence of exactly 15 residues, with no measurable contamination from other peptides mentioned above that also showed some activity. Hence this particular one was referred to as TCSF1, and its primary sequence of is:

$$
\begin{aligned}
& \text { gly }- \text { thr }- \text { pro }- \text { gly }- \text { gln }- \text { asp }- \text { val }- \text { val }- \text { cys } / \text { xxx } \\
& - \text { asn }- \text { gly }- \text { asn }- \text { thr }- \text { cys } / x x x-\text { asp }
\end{aligned}
$$

Residues 9 and 14 in the sample were consistently blank when sequenced. Cellular TCSF1 (observed mass:

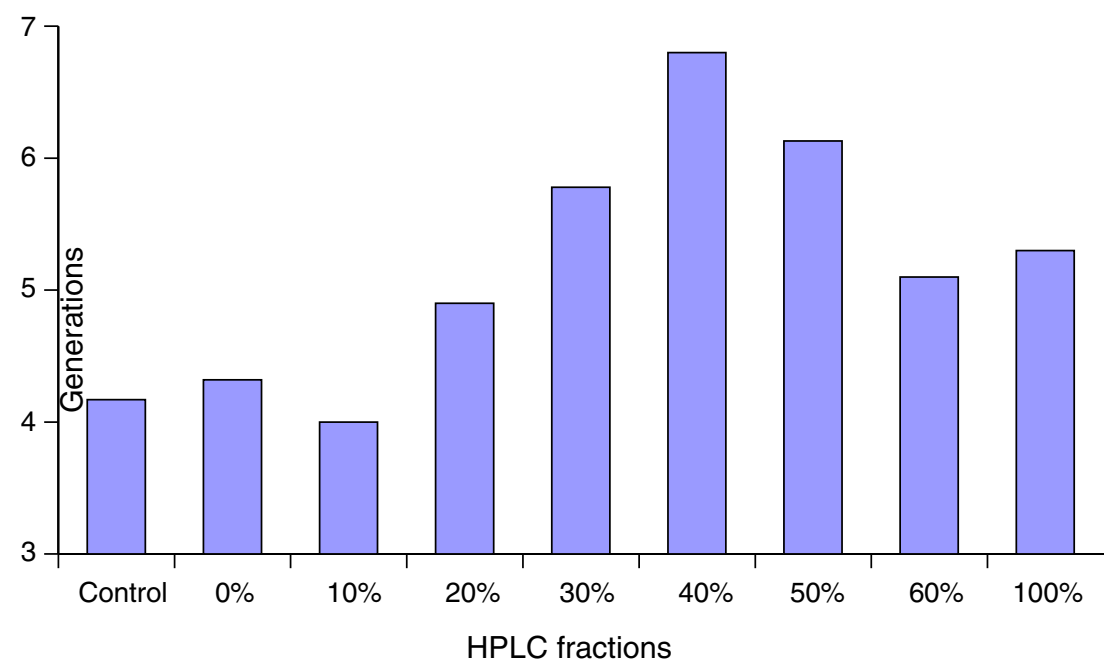

Fig. 1 Survival of T. thermophila cultures from 100 cells per $\mathrm{ml}$ supplemented with HPLC fractions, the $x$-axis relating the fraction to the strength of acetonitrile used in the preparation prior to lyophilisation. The $y$-axis gives the number of divisions (generations) the cells accomplished in $24 \mathrm{~h}$ 
Fig. 2 Conditioned medium separated on native $18 \%$ gel. The 15 clearest bands were cut from the gel and the proteins were extracted

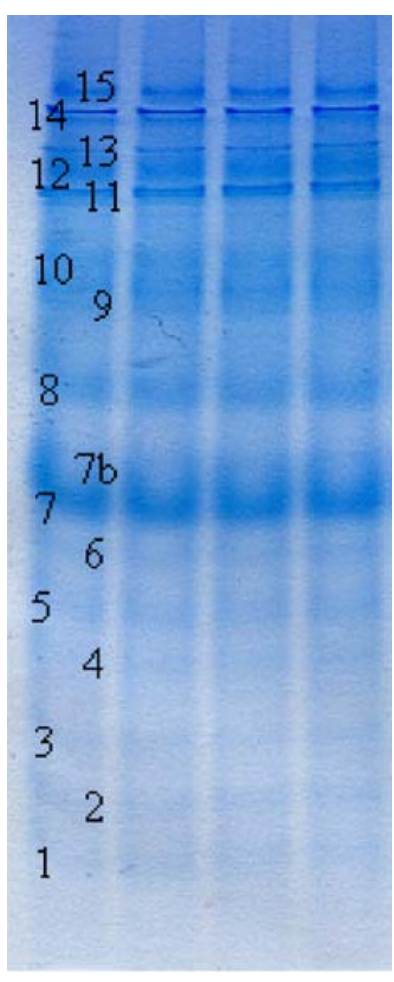

9,975 Da) was reduced and alkylated with 4-vinylpyridine, in order to elucidate if the sequence contained cysteine. The end product of the reaction was then analysed with mass spectrometry. The mass of the pyridylethylated peptide (observed mass: 10,717 Da) exceeded that of the native peptide by $742 \mathrm{Da}$, which corresponds roughly to the mass of seven pyridylethyl groups added to reduce cysteines per molecule of cellular TCSF1, suggesting the sequences:

\section{GTPGQDVVCNGNTXD \\ GTPGQDVVXNGNTCD or GTPGQDVVCNGNTCD}

Conditioned medium was separated on native acrylamide gel as described above, and the active gel-isolates $7 \mathrm{~b}$ and 12 were sequenced by Edman degradation. The sequences that have been established are:

\section{1: HHXQDIDWTQKGAVXP \\ 2: GNQXILQDFYNGLYQQ}

\section{Activity of synthetic TCSF1}

TCSF1 was synthesized with two cysteine residues, and dissolved into UHQ-water at a concentration of $1.5 \mathrm{mg} / \mathrm{ml}$.

Cell cultures at low and high seeding densities were supplemented with various concentrations of TCSF1 and the number of surviving cultures and generations were measured. Synthetic TCSF1 rescued low-density cultures at a concentration of $1 \mu \mathrm{M}$ TCSF1 (Fig. 4) and stimulated early cell proliferation in high-density cultures (Fig. 5).
Thymidine incorporation in cultures supplemented with native and synthetic TCSF 1

${ }^{3} \mathrm{H}$-thymidine incorporation was checked in early exponential phase T. thermophila cultures supplemented with synthetic $10 \mu \mathrm{M}$ TCSF1, native TCSF1 purified by HPLC or neither. Incorporation was higher in cultures supplemented with native TCSF1 at all times, while there was little difference in incorporation after the lag-phase between the controls and T. thermophila cultures supplemented with synthetic TCSF1 (Fig. 6). These differences were not reflected in the cell counts in such cultures, which were only marginally higher in cultures supplemented with native TCSF1 over the first $60 \mathrm{~min}$, after which all the cultures proliferated in parallel.

Stimulating effect on tissue cultures

Following the test of activity of TCSF1 on Tetrahymena cells. the same batch of peptide was added to cultures of FF9 and $3 \mathrm{~T} 3$ cells in $15 \mathrm{ml}$ RPMI medium with $0.2 \%$ foetal calf serum. The reduction in serum was a means of suppressing growth, in which case the cells die over the ensuing 34 weeks. Sets of cultures were given a full serum complement at weekly intervals to rescue any surviving cells. Only cultures given TCSF1 survived and proliferated beyond a two-week pre-treatment in $0.2 \%$ serum containing medium (Table 1 ).

\section{Discussion}

\section{Findings with Tetrahymena}

One manifestation of the need for signalling in the early survival of ciliate cells before outgrowth from a low inoculum is graphically illustrated by the following findings. Single Tetrahymena cells were inoculated into droplets of CDM with volumes of either 10 or $1 \mu \mathrm{l}$. In the larger volume the cells die with a half-life of $\sim 90 \mathrm{~min}$. In the volume of only $1 \mu \mathrm{l}$, almost $100 \%$ of cells isolated in this way create clones. It is surmised that the autocrine loop operates well within the smaller volume, but in ten times this volume it cannot reach a critical concentration within the same time frame as the low volume, and hence cell survival is compromised (Christensen et al. 1995).

A number of extracellularly secreted components are probably necessary for survival and proliferation of cells in culture. The ones we have purified from Tetrahymena rescues cultures at very low cell density, whereas without exception controls die. "Low density death" of Tetrahymena cultures in defined medium has been fully covered on several occasions (Christensen et al. 1998; Rasmussen and Rasmussen 2000b; Staarup et al. 1997), and these reports also indicate how rescue can be effected in a various ways. These include 
Fig. 3 a, b Conditioned CDM was separated on $18 \%$ native gels. Protein was extracted from the bands and used as a supplement to fresh medium. Cells inoculated into the test media divided more in $24 \mathrm{~h}$ as compared to the controls, when supplemented with protein from bands 2, 7-8 and 12. An inhibitory effect was observed when using supplements from bands 1, 6 and 14. Figure shows average values for three cultures supplemented with each band. Error bars are $1 \mathrm{SD} ; t$ test for "crude", 8, 9, 12, 13 and 14 gives their $p$ values a

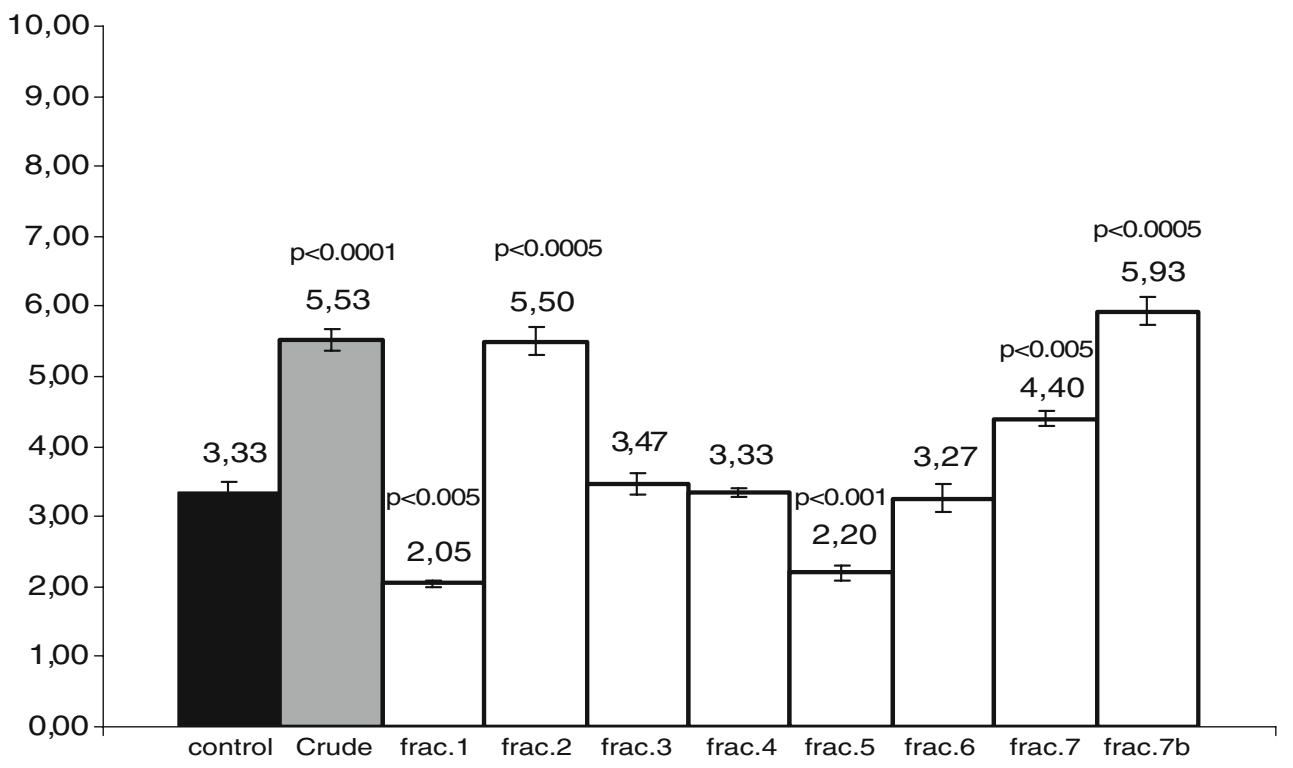

b

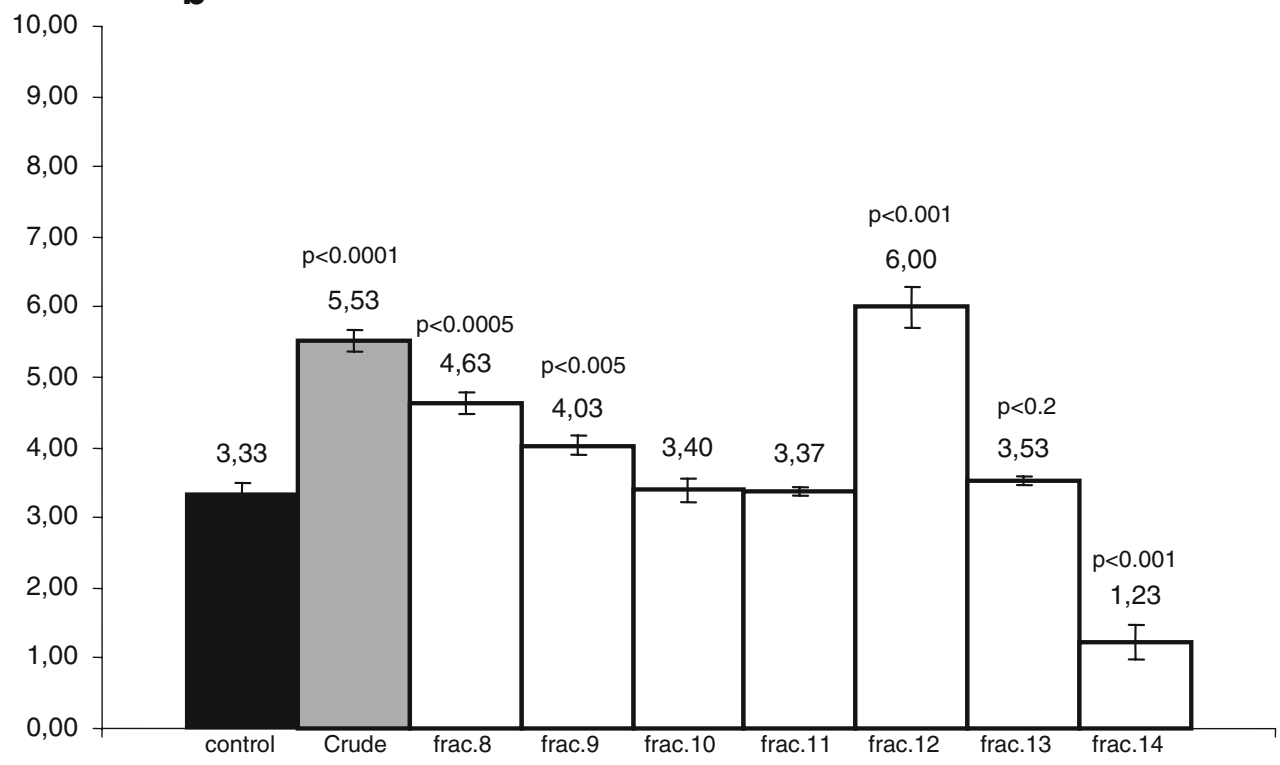

inhibition of lipolysis and activation of PKC, and since lowdensity death takes place during the early lag-phase, it has thus offered valuable insight in the intracellular processes in this period. No effect was observed when spent medium was added to already growing cultures.

A protocol for purifying a naturally secreted protein (TCSF1) in amounts sufficient to analyse and use in many tests has been presented above. Our current three-dimensional model of TCS1 as a dimer is shown in Fig. 7.

The results with the isolations suggest, however, that more than one protein or peptide might probably be involved in "rescuing" cells or preventing them from dying at low density. These were the peptide fractions at an MR of $\sim 9.9$ and at $\sim 17.3 \mathrm{kDa}$. At this time, we suspect the latter to be a dimerised form of the former, although this has still to be confirmed. Whether "unrelated" proteins to TCSF1 are involved seems unlikely.

Search for homologous sequences

The "Blast" search engine was used to look for homologies to the following motifs, which were all present in the biologically active fractions:
$1:$ HHXQDIDWTQKGAVXP
2 : GNQXILQDFYNGLYQQ
3 : GTPGQDVVCNGNTCD 


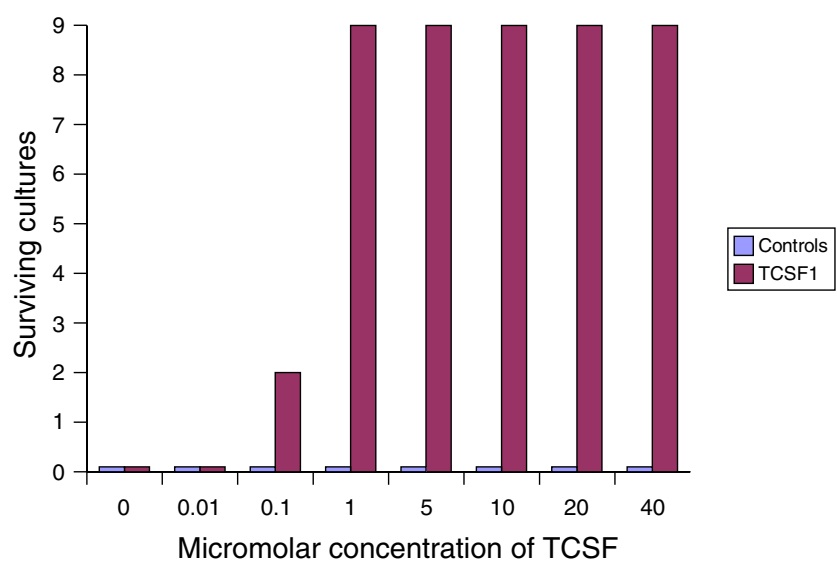

Fig. 4 Rescuing activity of TCSF1 synthesized from the HPLC G sequence. Synthetic TCSF1 rescued cells seeded a sub-critical density in all cases at concentrations higher than $1 \mu \mathrm{M}$

1. This sequence from the biologically active gel band 7$7 \mathrm{~b}$ has homology to a common motif in many types of cysteine proteases, and cannot be assigned to a particular protein per se. Cysteine dependent proteases constitute an important class of enzymes involved in the formation and hydrolysis of the amide bond in peptides from most cell types. Not only do cysteine proteases have vital roles in mammalian cellular turnover and apoptosis, they are also significant in the life cycle of many parasites (Olivier et al. 2005).

It is known that the majority of intra- and extracellular proteases in Tetrahymena are cysteine proteases. Straus et al. (1992) reported that at least four different proteases are present in $T$. thermophila supernatants. But they were not able to derive any sequences from their data. The only

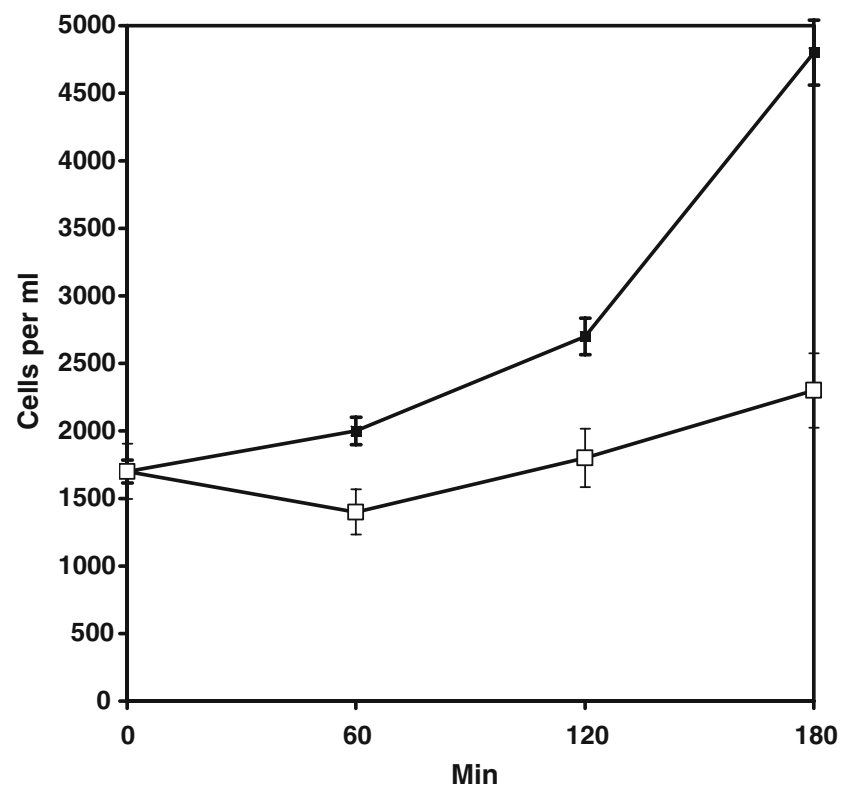

Fig. 5 Early proliferation in high-density culture (inoculated with 177 cells $/ \mathrm{ml}$ in CDM) of $T$. thermophila with synthetic TCSF1 supplement (filled square) or without (open square). Mean $\pm 1 \mathrm{SD}$

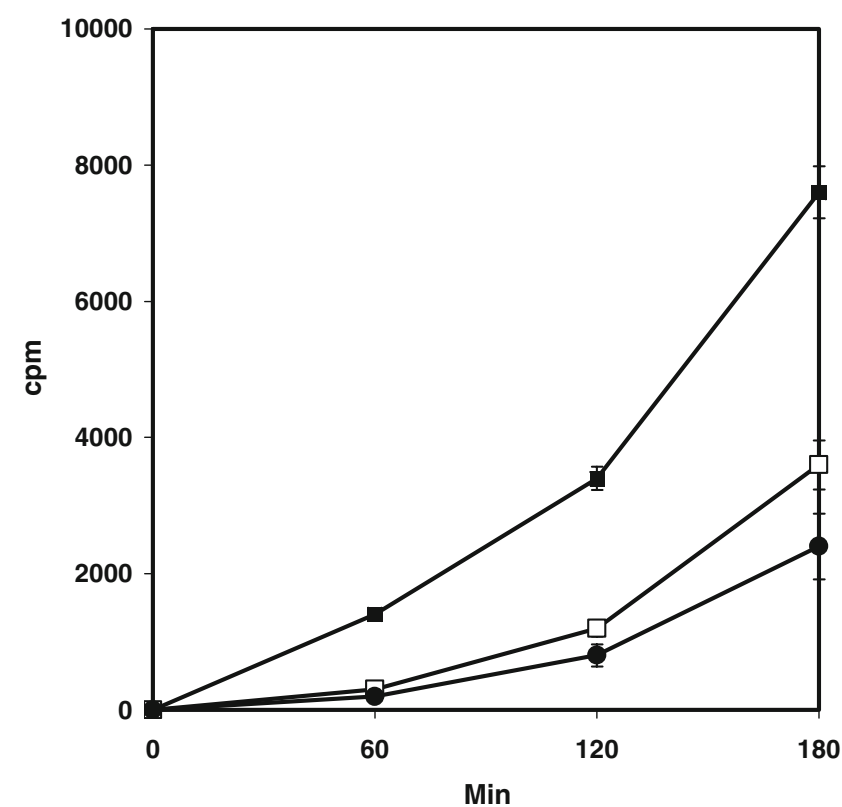

Fig. 6 Thymidine incorporation in T. thermophila cultures $\mathrm{f}$ similar density to those shown in Fig. 5, supplemented with native TCSF1 (filled square), synthetic TCSF1 (filled circle); or neither as the control (open square). Mean $\pm 1 \mathrm{SD}$

experimentally derived sequence information available on an active protease in growing Tetrahymena cells is Tetrain a T. pyriformis derived enzyme. A hypothetical Papain family cysteine protease containing protein has recently been predicted from reading the Tetrahymena SB210 genome (Eisen et al. 2006), and Herrmann et al. (2006), have purified sequences to suggest at least 6 extracellular cysteine proteases, with masses of $22-28 \mathrm{KDa}$ (Hermann et al. 2006). It therefore seems to be sufficient evidence to suggest that Tetrahymena cells do release cysteine protease (s) into the extracellular medium, and that these can be isolated.

2. This sequence was present in gel-bands $9-13$, and bears close homology to patterns present in Tetrahymena cytokinesis initiation regulation protein, $p 85$ (Gonda et al. 1999), in which the sequence (AT/DA) NQQILQDFYNGLYQQ is repeated five times. Gonda et al. reported the first pairs of residues in these motifs as Ala-Thr and Asp-Ala, and if it were indeed the same peptide being rediscovered, the same result would be expected, since the tested organism is the same. The results presented in this report, however, suggest that the two first residues of the gel isolates are Gly-Gln, while the first two residues of the M-peak protein are Ala-Thr and thus in agreement with the proposed sequence for $\mathrm{p} 85$. The amino acid sequence consists mainly of five repeats of two types. One type contains regions homologous to calmodulin binding sites, and one contains regions homologous to a part of a cdc2 kinase. It is not yet known whether p85 is kept as a 
Table 1 Fibroblasts and 3 T 3 cultures were inoculated at $\sim 2 \times 105$ cells per $60 \mathrm{~mm}$ Petri dish and grown in RPMI medium supplemented with $0.2 \%$ FCS \pm TCSF 1

\begin{tabular}{llllll}
\hline Days & 0 & 7 & 14 & 21 & 28 \\
\hline FF9, controls & 6 & 1 & 0 & 0 & 0 \\
FF9, TCSF1 & 6 & 6 & 6 & 6 & 6 \\
3T3, controls & 6 & 0 & 0 & 0 & 0 \\
3T3, TCSF1 & 6 & 6 & 6 & 6 & 6 \\
\hline
\end{tabular}

At 7-day intervals, a further $4.8 \%$ FCS was added to 6 cultures per group. After 14 days, only cultures given TCSF1 proliferated

whole or cleaved into individual repeats. The latter could explain the high concentration of the protein of $17 \mathrm{kDa}$ containing $\mathrm{p} 85$ homologous regions, and the widespread contamination of the neighbouring gel bands. Tetrahymena p85 was reported only as an intracellular protein, but being localised at the presumptive division plane before division furrow formation, it may be released into the medium during cell division, explaining the high extracellular concentration of this protein (Table 2).

3. Sub-sequences within the TCSF1 motif show partial homology with a large variety of proteins from many species. The Tetrahymena genome project has further predicted a series of hypothetical proteins, out of which five have degrees of homology with the TCSF1 motif (Eisen et al. 2006). The function of these proteins is unknown, but a sixth protein, showing similarity with the TCSF1 motif has been suggested to be a neurohypophysial hormone (Blast accession XP_001012514). An unnamed protein product from Paramecium also shows a motif with significant degree of similarity with the TCSF1 sequence, but apart from this, show little

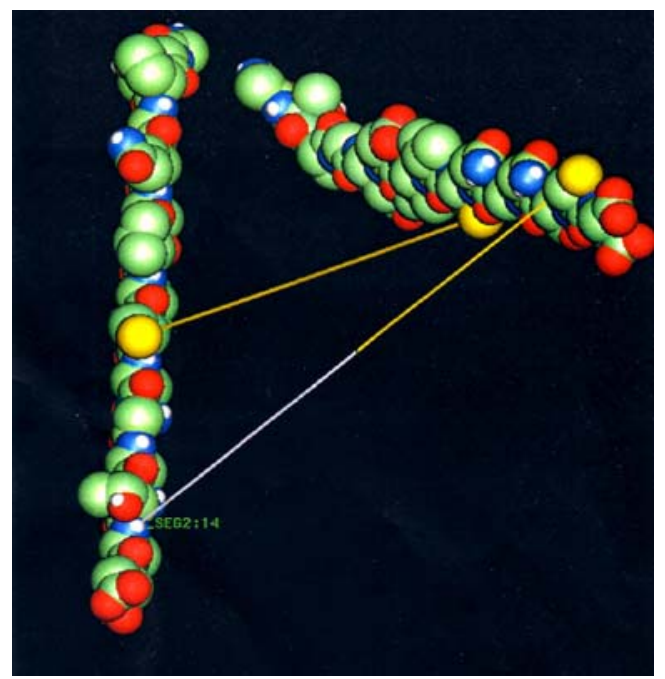

Fig. 7 The current three-dimensional model of TCS1 as a dimer-the colours are self-explanatory for a peptide and the two lines indicate possible disulphide bridges between the monomers homology with the Tetrahymena proteins. The hypothetical Tetrahymena proteins all have a strongly hydrophobic leader sequence of approx. 17 residues, which is followed by the hydrophilic TCSF1-like motif. Proteins destined for extra-cytoplasmatic compartments often contain a predominantly hydrophobic leader sequence, called the signal peptide, which plays a crucial role in increasing the efficiency of protein transport across membranes (Izard and Kendall 1994). This binds to the endoplasmatic reticulum, and transport is initiated before translation is complete (Watson 1984). Almost all of such signal peptides have methionine as their first residue, but generally show little homology in the primary sequence apart from this, yet they display similar physical characteristics (Watson 1984). A model for describing a typical transport sequence has been described as thus: a hydrophobic sequence of five to six residues, typically containing two positively charged residues, followed by 12 hydrophobic, uncharged residues. The sequence is terminated by 6 small residues, including glycine and/ or proline (Izard and Kendall 1994; Table 3).

The hypothetical Tetrahymena proteins follow the described pattern: the first five to six residues are hydrophobic and typically contain two lysine residues. This is followed by some 12 residues with primarily aliphatic side chains. The final six residues of the leader sequence reside within the TCSF1-like motif and include both glycine and proline residues. It can therefore be suggested that the Tetrahymena protein is targeted for transport into the extracellular matrix.

Another notable feature of the hypothetical proteins is a terminal stretch of serine repeats. Similar serine stretches are also present in transcriptional activators such as ICP4 (the major transcriptional regulatory protein of Herpes Simplex virus type1; Bates and Deluca 1998); nuclear shuttling proteins such as Nopp 140 Miau et al. (1997); and also transcriptional repressors belonging to the polycomb group of proteins, such as Pc1 and cramped (Tussié et al. 2001). All of these however, have only been reported as intracellular proteins. The fact that native, but not synthetic, TCSF1 increased thymidine incorporation, may lead to speculations that the intact protein may be involved in regulation of transcription, but too little is known about TCSF1 and the group of similar proteins at this juncture to be other than speculative on the reason for this difference.

Findings with other cell types

Fibroblasts kept at very low concentrations in medium containing $0.2 \%$ FCS survive much longer with TCSF1. Over a range of low serum concentrations that sustained 
Table 2 Homology between active fraction in Tetrahymena with other peptides

\begin{tabular}{llll}
\hline Entrez Accession & Organism & Length & Homologous Sequence \\
\hline N/A & T. thermophila & N/A & QDIDWTQKGAVXP \\
P32954 & Carica candamarcensis & 43 & SIDWRQKGAVTP \\
BAB13759 & Astragalus sinicus & 343 & DWRQKGAVTPV \\
SM9108 & Phalaenopsis sp. & 359 & IDWRQKGAV \\
\hline
\end{tabular}

Common residues in italics

slow growth (i.e. $>0.5 \%$ ), fibroblast growth was not significantly affected by TCSF1, suggesting that its action kicks in only at sub-critical serum concentrations when the signalling molecules within the serum have become too dilute to provide a sufficient proliferative stimulus; this again emphasises the difficulty of running similar (comparative) experiments between ciliates and mammalian cells. Little or no significant proliferation took place over the 2week period with reduced serum in the presence of TCSF1, but the important observation is that the cells survived in sufficient numbers such that as soon as favourable conditions were restored, proliferation began with little delay. This further emphasises our belief that a survival factor rather than a growth factor has been isolated. In this regard, we are not proposing that TCSF1 can substitute for or replace FCS, but that it can sustain cells, which would otherwise die within a week. We used fibroblasts in this study because their growth, especially from primary cultures, is limited with time if they do not undergo some form of malignant transformation. However, the question now to be considered is whether TCSF1 can provide the stimulus for other types of cells in culture to survive, and not just of mammalian origin.

More importantly, the remarkable finding is of crossphylum activity. It gives much encouragement to the possibility that cells can be kept longer and conditions manipulated so that a greater chance of "takes" for colony formation at low density might be improved, but a lot more research is needed. In instances where maintenance of a precious line depends on outgrowth from just a few remaining cells, TCSF1 could be invaluable. The possibility exists that some such factors will considerably reduce the exorbitant levels and quality of expensive sera that are required for adequate growth in some cell lines. Clearly a

Table 3 Homology between TCSF1 and closest matching peptides

Proteins Sequence

Hypothetical protein TTHERM_00489440

1 mikqllvisl svalvlagtp gqdvvcngnt ndvtscgpag gsswtagtts gskiadctal 61 saslsgifdt lcascqttnv yakstqdgci ntptaganva cyqsgscscg npptpafkwk 121 svdttncqia sclaapmpts sltdqfeasc gktntyansy gtacvnpsas ctrktgwtds 181 dckvcnasgt nssniyasad rtsctataps ssssssaiaf ssliiaslll

Hypothetical protein TTHERM_00488400 1 mikkllvlsl svalifagtp gadatcnsts dsttcgsaga stwttsttgg kfkitdctav 61 ggslsnifdt fetscpqsgn tyanaaqtgc sstpsagsnv acqsqgscpt sscgalpsaa 121 ftwtkasdtt ncvitsclaa pmpnsgltdn fctscsknkf ansygtacvn ptggncsrns 181 nwtdsdcqve naggknsanv kassdhtqcv aassssssvi avsallvasl li

Hypothetical protein TTHERM_00489470 1 mikkliilsl avtvilatat pgadvqcntn dqtscgssgg stwaqgtnpg kskiadegsi 61 gsslsnvydt lctscvtdsk nyansakngc qttvatpgav vpcqasgact tcgsispafa 121 wsipsgdttn ciitsclaap fptsnlidnf ckscggasgt yansygtscv astatcqntr 181 saawtdsdeq kcnaggansa nqyaaadsks cvstkpssss sssvivfscl ivaslli 1 mikkllvlsl svalifaaag $\boldsymbol{v d v n c n s t t d ~ s t t c g s a a a s ~ t w t q g a s g k f ~ k i s e c n n v g n ~}$ 61 sfsniydtfc ascpqggnsn iyanssksge vstavagtnv acqqgnactt ntcgalpspa $121 \mathrm{ftwskasdan}$ ncfitsclsa pmpnsgltdn fenscqstnk fanaygtacv npangsctrk 181 tnwtdddckl cnaggnnsan vkassdkssc vaasssssvi avsallvasl li 1 mikkllvlsl tvalifttpg advtcnsttd sttcgsagas twitgstagk fkiadcsavg 61 ssltnifdtf clscpqggns niyanasqsg crntpinngv niqcqqgsnc stscpalpla 121 ftwktglqpn qcmiescyaa pipnsgltfi lcgscspngd kpnsygtacv kttggfcdrn 181 qdwtdddcki cnaggknsan ikassdktqc vaaassssss viavsallia slli 1 mtilklfias llvyqifat $\boldsymbol{g}$ gdvtcsavt $\boldsymbol{c t t s g t c p n p}$ ptvpgsltwq nggdtgkcai

Neurohypophysial hormones, N-terminal Domain containing protein

61 nscpantqsg ltgasdlfcq scpgttvdgv kaiyantalt gcvaaietcg atraentwtn

unnamed protein product [Paramecium tetraurelia]. accession CAK73252 681 vasnslcsnf sgqnvvvnan tcaaienefp

The TCSF1 motif is highlighted 
mammalian homologue of TCSF1 would be highly preferable, but to date we have been unable to find any obvious homologue, although the search continues.

Acknowledgements MR was in receipt of a Danish Research Agency grant throughout the course of this work. We thank Professor John Fothergill and his staff of the proteomics unit (Department of Cell and Molecular Biology, University of Aberdeen) for help with protein sequencing. We are also grateful for comments on the manuscript from Professor Leif Rasmussen and Dr Søren Christensen.

\section{References}

Bates PA, DeLuca NA (1998) The polyserine tract of herpes simplex virus ICP4 is required for normal viral gene expression end growth in murine trigeminal ganglia. J Virol 72(9):7115-7124

Christensen ST, Wheatley DN, Rasmussen MI, Rasmussen L (1995) Mechanisms controlling death, survival and proliferation in a model unicellular eukaryotes Tetrahymena thermophila. Cell Death Diff 2:301-308

Christensen S, Rasmussen L, Leick V, Wheatley DN (1998) Signalling in unicellular eukaryotes: regulation of cell survival, proliferation, differentiation, mating, chemosensory behaviour, and programmed cell death. Int Rev Cytol 177:181-253

Christensen ST, Sorensen H, Beyer NH, Kristiansen K, Rasmussen L, Rasmussen MI (2001) Cell death in Tetrahymena thermophila: new observations on culture conditions. Cell Biol Int 25(6):509519

Eisen JA, Coyne RS, Wu M, Wu D, Thiagarajan M, Wortman JR, Badger JH, Ren Q, Amedeo P, Jones KM, Tallon LJ, Delcher AL, Salzberg SL, Silva JC, Haas BJ, Majoros WH, Farzad M, Carlton JM, Smith RK Jr, Garg J, Pearlman RE, Karrer KM, Sun L, Manning G, Elde NC, Turkewitz AP, Asai DJ, Wilkes DE, Wang Y, Cai H, Collins K, Stewart BA, Lee SR, Wilamowska K, Weinberg Z, Ruzzo WL, Wloga D, Gaertig J, Frankel J, Tsao CC, Gorovsky MA, Keeling PJ, Waller RF, Patron NJ, Cherry JM, Stover NA, Krieger CJ, del Toro C, Ryder HF, Williamson SC, Barbeau RA, Hamilton EP, Orias E (2006) Macronuclear genome sequence of the ciliate Tetrahymena thermophila, a model eukaryote. PLoS Biol 4(9):e286

Gonda K, Nishibori K, Ohba H, Watanabe A, Numata O (1999) Molecular cloning of the gene for $\mathrm{p} 85$ that regulates the initiation of cytokinesis in Tetrahymena. Biochem Biophys Res Commun 264(1):112-118 (Erratum in Biochem Biophys Res Commun $2000 ; 267: 478)$
Herrmann L, Erkelenz M, Aldag I, Tiedtke A, Hartmann MW (2006) Biochemical and molecular characterisation of Tetrahymena thermophila extracellular cysteine proteases. BMC Microbiol $6: 19$

Izard J, Kendall D (1994) Signal peptides: exquisitely designed transport promoters. Mol microbiol 13(5):765-773

Kaney AR, Knox GW (1980) Production of melanin precursors by a mutant of Tetrahymena thermophila. J Protozool 27(3):339-341

Miau LH, Chang CJ, Tsai WH, Lee SC (1997) Identification and characterisation of a nucleolar phosphoprotein, Nopp140, as a transcription factor. Mol cell biol 17(1):230-239

Olivier M, Gregory DJ, Forget G (2005) Subversion mechanisms by which Leishmania parasites can escape the host immune response: a signaling point of view. Clin Microbiol Rev 18 (2):293-305

Rasmussen MI, Rasmussen L (2000a) Phospholipase C and D in the commitment to survival or death in the early lag phase of Tetrahymena cultures. Cell Biochem Funct 18:133-139

Rasmussen MI, Rasmussen L (2000b) Are cells rescued from 'low density death' by co-operation between phospholipases C AND D? Cell Biol Int 24:121-123

Rasmussen L, Christensen ST, Schousboe P, Wheatley DN (1996) Cell survival and multiplication. The overriding need for signals: From unicellular to multicellular systems. FEMS Microbiol Lett 137:123-128

Schousboe P, Wheatley DN, Rasmussen L (1997) Autocrine/paracrine activator of cell proliferation: purification of a 4-6 KDa compound with growth-factor-like effects in Tetrahymena thermophila. Cell Physiol Biochem 8:130-137

Straarup EM, Schousboe P, Hansen HQ, Kristiansen K, Hoffmann EK, Rasmussen L, Christensen ST (1997) Effects of protein kinase $\mathrm{C}$ activators and staurosporine on protein kinase activity, cell survival, and proliferation in Tetrahymena thermophila. Microbios 91(368-369):181-190

Straus JW, Migaki G, Finch MT (1992) An assessment of proteolytic enzymes in Tetrahymena thermophila. J Protozool 39:655-662

Szablewski L, Andreasen PH, Tiedtke A, Florin-Christensen J, FlorinChristensen M, Rasmussen L (1991) Tetrahymena thermophila: Growth in synthetic nutrient medium in the presence and absence of glucose. J Protozool 38:62-65

Tussi-Luna MI, Bayarsaihan D, Ruddle FH, Roy AL (2001) Repression of TFII-I-dependent transcription by nuclear exclusion. Proc Natl Acad Sci USA 98(14):7789-7794

Watson MEE (1984) Compilation of published signal sequences. Nucleic Acids Res 12(13):5145-5164

Yin Z, Wheatley DN (1994) Sensitivity of 3 T3 cells to low serum concentration and the associated problems of serum withdrawal. Cell Biol Int 18:39-47 